\title{
Reporting Radiation and Other Risk Issues in Norwegian and Swedish Newspapers ${ }^{1}$
}

\author{
Åsa Nilsson, Jon B. Reitan, Arnfinn Tønnessen \& Ragnar Waldahl
}

\section{Introduction}

Modern man lives in a "risk society" in which the many hazards representing a threat both to each individual and to society as a whole have become a dominant theme (Beck 1992, Luhmann 1993). However, hazards differ in terms of how people perceive and respond to them. Risk characteristics have a bearing on how acceptable people find them to be. Some hazards are visible and well known in everyday life, which mean that people to a large extent may influence what kind of risk they expose themselves to through various types of behaviour. Smoking and base-jumping are examples of risk behaviour decided at the individual level. Other risks are present in less visible arenas, without any direct link to people's everyday life. Thus it is difficult for the public to determine when and to what degree they may be exposed to such risks. Ionising radiation is a prime example of such a kind of risk without visibility and unfamiliar in people's everyday life.

Both risks of a more familiar and unfamiliar type plays a key role in today's society, and it is important that each individual be capable of evaluating what risks they expose themselves to in different situations, and how they may protect themselves against them. Personal experience is of course important in this regard but in our increasingly complicated way of life personal experiences must be supplemented by expert based knowledge and the knowledge accumulated in society. This

Radiation Risk Project, University of Oslo/NRPA, Pilestredet 46, NO-0167 Oslo,

arnfinto@media.uio.no (project coordinator) need for a risk information supplement paves the road for the mass media to play a key role. The role played by the media deserves attention for at least two reasons. First, the mass media are the most important and widespread way of communicating with the majority of society, and second, risk issues are difficult to convey and there are many ways in which the public can be underinformed, misinformed, or even deceived.

This second aspect, which calls on the field of "risk communication", is of special importance in the case of risks where establishing the "true facts" may be hard and even impossible. Examples can easily be found today of hazards whose possible later effects are uncertain and very difficult to anticipate: one need only to think of genetic engineering or of the unexpected impacts of the "mad cow disease". The kind of risks the mass media cover, and the manner in which these risks are compared to each other, arguably will have an impact on how people will perceive and understand them. No less important is how the magnitude of risk attached to various behaviours is described: are unlikely dangers portrayed as requiring vigilance? On both accounts it is easy to convey a biased picture of the facts, resulting in large consequences both for the individuals' feeling of personal security, and for societal demands for risk prevention and reduction.

The mass media are particularly important when it comes to risks normally beyond the realm of personal experience where they serve - directly or indirectly - as an important link in generating and shaping the public awareness of the hazard. For these risks the public at large is very much dependent upon the priorities and judgements made by the mass media. Both the publics' awareness of a specific hazard and estimation of risk level repre- 
sented by that specific hazard may very well be shaped by the mass media coverage.

Radiation is the transport of energy by electromagnetic waves or atomic particles, and is often categorised in two types: ionising radiation (hereafter IoR) and non-ionising radiation ${ }^{2}$. If IoR penetrates living tissue it may sometimes affect normal biological processes. Exposure to any of the common types of IoR: alpha radiation, beta radiation, gamma rays, $\mathrm{X}$-rays and neutrons, may thus have effects on health. Particularly, the development of cancer over decades and heritable effects over generations has been mentioned. Natural background radiation is the part of IoR that is naturally and inevitably present in our environment, the level of which may vary greatly. Much of our natural IoR exposure is due to radon, a gas that seeps from the earth's crust and is present in the air we breathe Man made IoR exposure is a very heterogeneous group where we find: medical uses of IoR, nuclear bomb test fallout and also nuclear accidents like the Chernobyl accident. Radon and medical uses of IoR are found in many countries to be the main sources affecting the public, but the preoccupation among the public related to the various types of IoR does not at all seem to reflect the relative weights of actual exposure. In fact, among nuclear technocrats, typically in an International Atomic Energy Agency expert meeting, one will often hear arguments that the public is preoccupied with the "wrong" types of IoR. According to such expert opinion, the public should rather be concerned with their current main exposure sources ("dose contributors") than worrying about the possible high consequence but low probability risks related to possible future nuclear accidents. In fact, mass media coverage of man made IoR sources is sometimes pointed to as an "explanation" of how the public have been "misled" to being overly concerned with the "wrong thing".

IoR risks have through the peaceful use of nuclear energy for electricity production been receiving much attention for an extended period, especially in relation to the nuclear accidents such as Three Mile Island and the Chernobyl accident, but lately also related to the risk for nuclear terrorism (Mærli 1999). As a phenomenon not detectable by our senses and with possible delayed, severe consequences for those affected, it is a very difficult issue for the common public to relate themselves to, and it has been documented that large discrepancies exist between the public and the experts' risk judgement in this area (Drottz Sjöberg 1991, Slovic 1987). A discrepancy that some researchers have claimed to be caused by the biased coverage of this area in the mass media while other have noted "Each side, expert and public, has something valid to contribute, Each side must respect the insights and intelligence of the other" (Slovic 1987:285).

The mass media's coverage of the risks associated with IoR should also be seen in the perspective of how society utilises various types of IoR. It seems for instance reasonable to assume that the mass media in countries with a large nuclear industrial sector will have a different overall perspective than in countries without a nuclear industrial sector, not least as various interest groups quite probably influences or try to influence the public debate. Norway and Sweden offer an example of two otherwise quite similar countries clearly different in terms of nuclear energy position.

While Sweden since the 1970's has had electricity production based on nuclear power, Norway has had none. In fact, in Norway there only exist two small research reactors used for scientific purposes. Thus while the public and political discourse about nuclear power in Sweden has been extensive this issue has never surfaced to any particular attention in Norwegian political debate (cf. Holmberg and Asp 1984). It seems reasonable that such contextual differences will influence the newspaper coverage of this area, and a comparison of Swedish and Norwegian mass media coverage of IoR risks will highlight how interest groups and governmental policies in this area influence and make themselves present in the mass media coverage.

The present analysis concerns newspaper coverage in Norway and Sweden, and the following key question is asked:

\section{- How do the newspapers in Sweden and Norway report on risks associated with IoR?}

More specifically four questions are addressed in the analysis. First, the coverage of IoR risks is compared to the coverage of other risks.

- The selection of hazards: To what extent do the newspapers inform their readers about the various radiation risks compared to other risks, and how prominent a position was the radiation risk stories given as news issues? Was it for instance found that such risk forms are given a particular weight, or do the more everyday risks receive the same kind of attention?

Second, attention is turned specifically to the journalistic coverage of various IoR risks. Three specific questions are asked: 
- The risk information provided: How were radiation risks, their consequences and targets depicted?

- The risk context: To what extent was the radiation risk shown to be related to other risks? Was risk seen as controllable by the individual? Was there focus on conflict between different "risk actors" ? etc.

- The sources of risk information: Who appeared as risk definers in the stories?

These questions are, after a short description of data and methods, analysed in the following four sections of the article. We then discuss risk reporting in relationship to the principle of news value before we make our conclusions.

\section{Data and Methods}

The point of departure for the current analysis is the 10-year commemoration of the Chernobyl accident on April 26th 1996. For eight weeks - four weeks prior to the date and four weeks after newspapers were examined for their stories on a range of risks, including IoR risks. The method used in the study was a quantitative content analysis, carried out by means of an extensive code form comprising more than hundred variables. The anniversary event gave attention not only to the Chernobyl accident but highlighted also other risk aspects associated with nuclear energy and IoR at a broader level. This selection of a time frame naturally provides more media coverage of IoR risk issues than would be expected from any other randomly selected period. One major advantage being that it is possible to study the newspaper coverage of this field in a period where it is known beforehand that a specific IoR risk issue is put on the societal agenda. Something that will give eventual findings a firmer standing also as a sufficient number of items is needed for running the data analysis in a quantitative content analysis.

In both countries, the chosen time period can be regarded as quite typical in terms of events and situations that might affect media reporting. Two things, however, should be mentioned. One was an exclusively Swedish matter: a newspaper strike that affected two ${ }^{3}$ of the investigated newspapers during a five-day period. The other aspect was an event of wider geographical relevance, with definite implications for a study on risk reporting: On March $26^{\text {th }}$, i.e. around one week before the study period was set to begin, the UK government made an announcement concerning the research findings indicating that the "mad cow" disease might well be transmitted to humans ${ }^{4}$ (Will et al, 1996) and a broad coverage of the disease and the scientific controversy was started. It is however not very probable that the coverage of BSE substantially influences the specific character ${ }^{5}$ of the IoR risk coverage. A benefit of the BSE crisis for our study was an opportunity to compare the coverage of IoR risks to the coverage of another "invisible" risk, which also may negatively influence the public.

The selection of newspapers - five from Norway and six from Sweden ${ }^{6}$ - was pragmatic rather than representative. First choice was made of large scale national papers, due to the simple assumption that the more readers, the more possible impact on the population. Second, because the RISKPERCOM project of which the media study was a part, made many different measures of how people perceive risks in the Chernobyl anniversary context, we needed papers from regions severely affected by the Chernobyl fallout. We expected that the newspapers chosen from such regions, Valdres and Oppland Arbeiderblad in Norway and Gefle Dagblad in Sweden, would be comparatively more attentive to the Chernobyl anniversary.

Both the selection of the study period and newspaper sample has to a certain extent influenced our findings. The selection of period because the priorities of news in the newspaper will always be influenced by events occurring in society. The selection of newspapers because representativity of newspapers has not been aimed at. The selection of newspapers may possible influence the comparison between the Swedish and Norwegian coverage, as one may claim that the selected Norwegian newspapers to a larger extent are local papers. But within these limitations the results derived from this study will give important information on the role of mass media within the field of risk communication, with special emphasis on radiation risks.

\section{Risk Extent and Prominence}

Empirical research does not unanimously support the intuitively pleasing notion that the number of victims or expected number of fatalities should correlate with the volume and intensity of media coverage of hazards (Adams 1986, Combs \& Slovic 1979, Singer \& Endreny 1987, 1993 cf. Nimmo \& Combs 1985; Sood et al. 1987; Wilkins \& Patterson 1987). Rather as Greenberg et al. (1989 a\&b) suggest, media networks rely on traditional journalistic determinants of news - thus overesti- 
Table 1. Frequencies and Total Volume of Risk Stories (percentage)

\begin{tabular}{|c|c|c|c|c|}
\hline & \multicolumn{2}{|c|}{$\begin{array}{l}\text { Numbers of stories primarily } \\
\text { devoted to the hazard }\end{array}$} & \multicolumn{2}{|c|}{$\begin{array}{l}\text { Total volume devoted } \\
\text { to the hazard }\end{array}$} \\
\hline & Norway & Sweden & Norway & Sweden \\
\hline Road traffic accidents & 33 & 22 & 21 & 21 \\
\hline Alcohol consumption & 15 & 12 & 13 & 11 \\
\hline BSE & 12 & 22 & 13 & 17 \\
\hline Floods & 5 & 1 & 7 & 1 \\
\hline Air pollution & 15 & 15 & 16 & 11 \\
\hline Chemical waste & 3 & 10 & 3 & 10 \\
\hline Chernobyl accident & 6 & 6 & 11 & 18 \\
\hline Military use of nuclear technology & 3 & ** & 5 & ** \\
\hline East European nuclear power plants & 2 & 2 & 3 & 2 \\
\hline Domestic nuclear power plants & * & 5 & * & 5 \\
\hline Nuclear waste & 2 & 2 & 3 & 2 \\
\hline Radiation from in-home radon gas & 2 & ** & 2 & ** \\
\hline Other risks & 2 & 2 & 3 & 1 \\
\hline Percent & 100 & 100 & 100 & 100 \\
\hline $\begin{array}{l}\text { Total numbers of stories } \\
\text { and column centimetres }\end{array}$ & 1310 & 1587 & 55442 & 75430 \\
\hline
\end{tabular}

* Norway have no domestic power plants.

** Less than $0.5 \%$

mating sudden and violent risks, whilst underestimating chronic ones ${ }^{7}$.

The present analysis clearly demonstrates that ten years later, the Chernobyl accident was considered a newsworthy issue both in Norway and Sweden. From Table 1 it can be seen that, within the covered period, about six percent of all risk stories in the newspapers primarily treated the Chernobyl accident. This issue was, however, far from the only radiation risk item dealt with. The newspaper also dealt with other kinds of radiation risks, and by treating all the nuclear items as one single category, it can be seen that this group accounted for about 15 percent of all risk stories in both countries. Even if this is quite a significant proportion; it is for instance less than half the amount that Norwegian newspaper dedicated to the coverage of traffic accidents, and the Swedish newspapers had more news stories about both traffic accidents and BSE.

However, the Chernobyl commemoration coverage did show a very focused pattern, and the prominence was larger in a more limited period around April $26^{\text {th }}$ than in the total 52 days we studied. Four out of ten Chernobyl items was found in the April $25-27^{\text {th }}$ period, and seven out of ten occurred in the period five days before - five days after April $26^{\text {th }}$. Thus, Chernobyl risk stories alone accounted for one out of five of the total number of risk stories in this 11-day period. It is also evident from table 1 that the proportion of volume devoted to Chernobyl risk stories was about twice the proportion of other risk articles, in fact, in the 11-day-period nearly half of the total newspaper volume devoted to risk coverage was purely Chernobyl commemoration coverage.

Prominence is a typical way of estimating the editorial importance as well as the potential public impact of a journalistic theme. One of the features we measured, in order to gain an idea of the prominence given to the Chernobyl issue, was volume: how many square centimetres were devoted to the theme? Compared to the other risk themes studied in the same period, Chernobyl stories were clearly outstanding in the large volume they were granted by editors. Longer, larger feature stories were used when reporting on this theme.

Naturally, it is difficult to interpret results concerning story frequency without relating them to what has "actually" been going on in the "real world" (Rosengren 1970). Such objective data are, however, hard to assemble and to summarise and compile into a clear-cut picture. This holds especially true with regard to radiation risks, to which it is very difficult to relate actual causes of death. Considering the fact that Road traffic accident was 
an item ranked very high with regard both to volume and story frequency, the newspapers cannot be charged of focusing only on newsworthy "high consequence low probability risks", such as the ones connected with nuclear power energy (Singer \& Endreny 1987:10ff).

Leaving the total picture, it becomes clear that there was considerable variation between the different newspapers with regard to how they prioritised the coverage of different hazards. In Norway the local newspaper Valdres, whose circulation area was severely affected by the radioactive fall-out ten years back in time, accounted for the largest share of Chernobyl stories: 15 per cent of the total number of risk stories. The other newspapers ranged from 3 to 9 per cent in this regard, including the other local paper, Oppland Arbeiderblad, with a similar geographical background to that of Valdres. The most plausible explanation for this difference between the two local papers is the fact that the main subscription area of Valdres was much more seriously affected by the Chernobyl fall-out than the subscription area of Oppland Arbeiderblad (Skurdal et al.1987). The same pattern was found in Sweden. The local morning paper, Gefle Dagblad, whose circulation area was the most affected in Sweden, prioritised stories about Chernobyl more than the urban morning papers and the tabloids. Local papers from areas affected by Chernobyl fall-out were clearly much more concerned with this type of risk items than other papers.

We have made a distinction between the newspapers" "ordinary" and "less ordinary" coverage. The former refers to such day-to-day reporting that is very much a result of what is "actually" going on in the "real world", whereas the latter refers to all other kinds of contents, which to a larger extent are the result of the newspapers' own choice: which issues to highlight and which not. Obviously, both definitions are based on a gross simplification of the news process; however, it is the comparison between the two, which should be stressed.

In total, almost three-quarters of the newspaper stories were of the ordinary news type. On the whole, the conclusion reached by Wilkins and Patterson (1987:81), that "news generally focuses on discrete events, not on the underlying issues that gave rise to them", is hardly contradicted by our results. Road traffic accidents represented the hazard most clearly treated as an ordinary news item - that is, the event was reported in a terse manner, and the hazard gave rise to no feature stories, editorial comment, or background research articles. In con- trast, feature stories were, proportionally, most often published regarding the Chernobyl accident, whereas Air pollution and BSE were most often treated in analyses, columns, or commentaries, more or less thoroughly discussing or reflecting on the risk issue in question.

It could be argued that results regarding the volume of risk reporting in the media represent findings of a rather limited value, as long as the actual message conveyed is left unconsidered. However, the frequency and volume with which newspapers provide stories about certain hazards have been found to be important factors per se in determining people's perception of risk, the mere amount contributing to a negative evaluation being made by the media-consuming public (Mazur \& Lee 1993: 682ff; Wiegman et al. 1989). These findings have resulted in an elaboration of the widely supported agenda-setting theory: the "quantity of coverage" hypothesis. This hypothesis suggests that the agenda-setting theory makes too weak a claim by advancing only that the media influence what people think about, without acknowledging their power to shape the directions of these thoughts. Hence, under the "quantity of coverage hypothesis", one could assert that the frequency and volume of risk reporting is indeed important, since it may, in a cumulative sense, contribute to making the public attentive to and concerned about a specific hazard. Not only do people come to understand that they should be thinking about the hazard, they also deduce from the quantity of coverage that the hazard is a serious one. Or, to dare the inverse logic of that hypothesis: what the public is not told about, the public does not fear.

As demonstrated above the Norwegian and Swedish newspaper did pay broad attention to various IoR risk in the study period influenced by the ten-year Chernobyl anniversary event. Even though more everyday risks like traffic accidents and alcohol received as much or even more coverage, the rest of this article focus mainly on the newspapers coverage of IoR risk, but keep some other risks like Air pollution and Chemical waste for comparisons purposes. In order to avoid overshadowing of the IoR data, the discussion now will exclude three of the four most frequently reported hazards, Road traffic accident, Alcohol consumption, and BSE, together with Floods. These items excluded, together with hazards producing no more than 15 stories, meant that the basis for the further analysis is reduced from 1310 to 429 stories in Norway and from 1587 to 639 in Sweden. 


\section{Risk Messages and Information.}

The mass media have been described as event-centred and tending to focus on accidents and disasters rather than on more "invisible" risks, and to report on harms - that is, damage suffered - rather than on risks - or potential for damage (Singer \& Endreny 1993:6f, Wilkins 1986, Wilkins \& Patterson 1987:82). The present study shows, however, that Norwegian and Swedish newspapers, when treating nuclear and IoR risks as well as risks related to Air pollution and Chemical waste, are not only concerned with accidents or other actual consequences of risk, but also of potential risk situations. In total, this holds for three-quarters of the stories. (The degree to which the information provided might be useful to readers in terms of risk prevention is another question, however not considered in the present study; cf. Singer 1990).

Nuclear hazards being of the type "low probability-high consequence", it is obvious that the media normally do not have much of a choice between a risk and an accident focus. Hence, the question should perhaps be rephrased: why is it that the media cover nuclear risks at all? An obvious answer would be that editorial policy is influenced by earlier evidence of the fact that nuclear techniques may result in dangerous consequences (Smyser 1991:244). The issue has already at earlier stages been defined as "news" (Nelkin 1989:59), and, as Mazur and Lee (1993:714) put it: "[...] once an issue has reached the plateau of journalistic attention, stories come easier, and items that once seemed uninteresting now become publishable". The risk dimension of nuclear power has become widely accepted, and therefore a legitimate issue of concern. Our analysis also revealed that one quarter of the stories dealing primarily with the accident at the Chernobyl reactor, still focused on risks connected with the accident rather than on the actual consequences brought forth by it. This indicates that the accident is indeed considered a current problem, entailing unrealised and more or less unknown and incalculable consequences.

Most of the risk stories appeared in some kind of geographical context, informing the reader, if not necessarily explicitly in which geographical area the hazard was likely to be found, at least where there was a concern for the hazardous situation. Somewhat more than one quarter of the risk stories were told in a local context, and the local papers in both countries were, not very surprisingly, most inclined to provide a local risk focus. When widening the geographical scope, it was found that more than half the stories still kept to the domestic sphere. If adding also those stories containing both a domestic and foreign focus, the proportion grows to two thirds, with Air pollution related most clearly to all geographical levels: local, domestic, foreign, and global. The Chernobyl stories also varied in this respect, the East European focus slightly more common than the domestic one.

With regard to risk consequences, such information was not very prominent in the IoR risk stories compared to the other risk stories. Those IoR stories treating the Chernobyl accident (and Military use of nuclear technology in Norway) were more informative in this respect than those treating $\mathrm{Nu}$ clear waste and East European nuclear power plants (and Domestic nuclear power plants in Sweden). When a story did contain such a focus, it most often referred to effects on human health or the environment. The stories in the Norwegian newspapers focused, however, more on death as a consequence of the Chernobyl accident than did the Swedish, which instead more often focused on illness in term of cancer. The Norwegian newspaper also focused more on environmental aspects than the Swedish one. Consequences for the economy, employment, or property were seldom brought into focus, and all in all it seems that the newspaper reading public got a rather poor opportunity to take up a position in the nuclear energy debate, at least when it comes to one based on risk.

Negative news sells and news professionals are often said to work according to a maxim of their own: "Bad news is good news. Good news is no news." (Cohn 1989:43). Or as Westerståhl and Johansson (1985) say rather cynically: the mass media are constantly selling anxiety. This has implications for each specific story as well as for newspaper coverage on the whole, and the question is if this also is an appropriate conclusion considering the results gained from the present study.

Headlines and articles were rated for their tone: neutral, alarming or reassuring. Overall, neutrally phrased headlines dominated, but alarming headlines were more frequent than reassuring ones for all seven hazards. After excluding Air pollution, where almost nine out of ten headlines were neutral, the rest of the risk stories had $27 \%$ alarming as compared to $5 \%$ reassuring headlines. Turning to the story messages as a whole, the results shown in table 2 clearly suggest that the newspapers in both countries tend to focus on alarming risk aspects. In nearly all the hazard types, two thirds or more of the stories included some alarming state- 


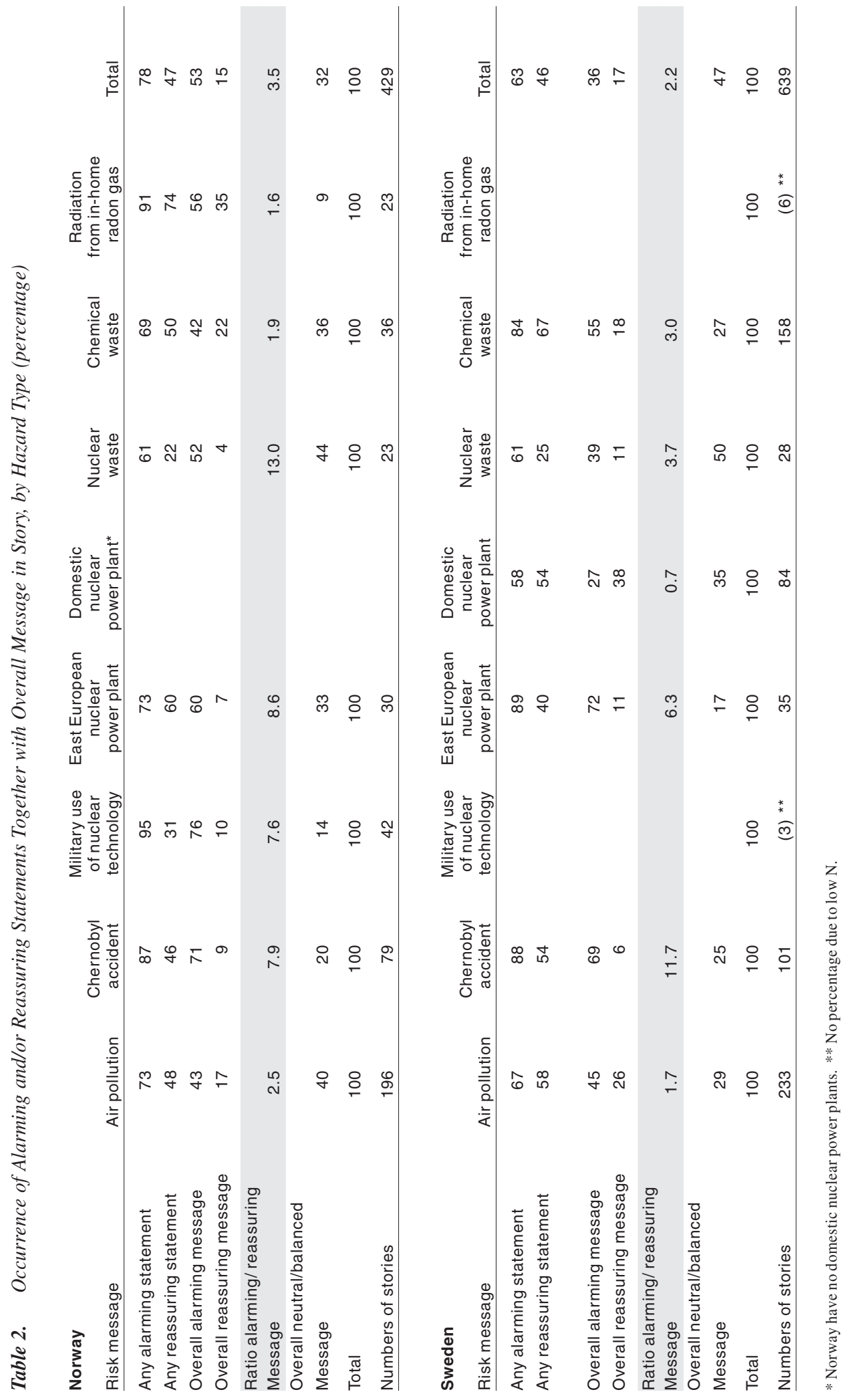


ment, whereas reassuring statements seldom were found in more than half of the stories. Furthermore all the nuclear hazards were very often dealt with in an alarming context in the Norwegian newspapers, whereas the Swedish newspapers made a clear distinction between domestic and international items. In Norway it was found for the nuclear items that the alarming messages were between 7.6 and 13 times as common as the reassuring ones, with nuclear waste at the top. In Sweden the stories on the Chernobyl accident (11.7) and on East European nuclear power plants (6.3) showed a remarkable ratio, while the two domestic nuclear items, Domestic nuclear power plants and Nuclear waste, were presented in a much more reassuring perspective. Across the two countries and the eight risks stories displayed in table 2. Domestic nuclear power plants in Sweden are the only hazard receiving a majority of reassuring story treatments.

These results show that nuclear hazards are treated in an overall alarming way in both countries. The difference between Sweden as a "nuclear energy nation" and Norway as an almost "nuclear free zone" is nevertheless obvious, and most clearly demonstrated in the newspaper stories on Nuclear waste. While this hazard has the highest ratio between alarming and reassuring messages in the Norwegian newspapers, the corresponding ratio in the Swedish newspapers is much lower, and it seems that this item is understood in a less frightening way by Swedish journalists than by their Norwegian colleagues.

The non-nuclear items represented in this study are all treated in a much less alarming way both in Norway and Sweden. This difference is especially interesting with regard to Radiation from in-home radon gas, which has the "best" balance between overall alarming and reassuring messages. Although radon accounts for the most significant part of the mean radiation dose to the Norwegian and Swedish population, it seems to be little associated in the media with other IoR issues, in the sense that it is not treated in a predominantly alarming way. One reason for this may be that radon is regarded as a "natural" risk, and other nuclear risks as "technological". It might further be speculated that the "nuclear" feature of risk to many people implies grave common symbolic values flavoured by Hiroshima and destruction, whereas e.g. diagnostic radiology (another IoR application) is considered part of caring. There is no obvious reason why journalists should have unusual perceptions in this regard (Smyser 1991). Still, this result contributes to the ongoing debate about whether the public should be actively alerted to the risks of domestic radon.

These results, even if they are very clear, should be handled with care. It is very difficult to estimate the effects of "alarming" as opposed to "reassuring" risk messages. One reassuring message does not necessarily "balance" or "negate" one alarming message, and a definitive conclusion neither can nor should be reached until audience responses are studied in conjunction with the content analysis (Gorney 1992:464).

\section{Risk Story Context}

The attitude towards a certain risk is not only influenced by specific and "objective" risk qualities, but also by other factors embedded in the risk context. The mass media is an important source of information in this respect, especially when it comes to hazards normally beyond the experience of the general public, such as those of a distinctly scientific and technological nature. The news story context and the media style of presentation are often considered important with regard to public attitudes and actions (Nelkin 1989:54, Renn 1992:478, Sandman et al. 1993).

One intuitively pleasing factor in this respect is whether or not the media report on any measures taken (or considered) by society, in order to prevent the risk or else to mitigate impacts. Information of this kind was provided in nearly half of the stories examined in both countries, but there were greater variations between the specific hazards in Sweden than in Norway. In general, the newspapers described the measures taken or considered in a neutral, or, positive light.

Benefits represent another interesting aspect of risk context. The question of possible gains that may balance risks (and justify continuation of a risky activity) was rarely brought forward in the stories. Considering the nature of the hazards included in the analysis, this must be regarded as a rather self-evident result (Singer \& Endreny 1993:90ff; 125). In Norway, however, the energy benefits associated with East European nuclear power plants were indeed mentioned in 5 out of 30 stories. In only one case were those benefits evaluated in a positive manner. Thus, whether a fair situation or not, we must conclude that benefits related to East European nuclear energy were rarely recognised by the newspapers in the spring of 1996.

Individual control represents another important factor when it comes to people's perception of risk, 
but this dimension was almost never attended to, neither in the Swedish nor in the Norwegian newspapers. This result was unexpected. Individual control is a dimension that could be reported to bring human interest into a news story; as such, it might influence the news gathering process (Hvitfelt 1986). Risk stories might hypothetically be covered for the very reason that the hazard in question is regarded as uncontrollable. Moreover, in a 1993 Norwegian survey on Chernobyl coverage at the time of the accident, people specifically asked for information to enhance individual control, that is, people would have liked to find advice for their own emergency behaviour (Tønnessen et al. 1995). Such a demand, if expressed in society, might induce the media to follow up on the issue of individual control. However, explicit references to individual control, or the lack of it, were rare, as was practical advice.

The generally small number of stories providing practical advice could hardly be said to meet the condition needed if the press wanted to contribute to better functional knowledge among their readers (Waldahl 1995:110). This is perhaps a regrettable situation. Successful risk communication is certainly a difficult task, and advice is far from always effective in producing changes in knowledge or in behaviour (Maibach and Parrot 1995). Still, as difficult and complex as risk information in general and successful advice strategies in particular may be, efforts made in this direction would probably be well-spent (Tønnessen et al. 1995). ${ }^{8}$

Taking on the rather negative position that "bad news is good news", it is, on the basis of the context variables discussed above, tempting to create a "best case scenario" for journalistic risk reporting. Hazards which might be connected with public anxiety, insufficient, incorrect or total absence of measures taken by society, suppression of risk information, conflict ${ }^{9}$, blame, ethical aspects and/or expressed contempt for risk regulators, might be suspected to be deemed more newsworthy than a risk issue lacking these kind of dimensions (cf. Renn 1992:481). One of the hazards covered by the present analysis was especially "well matched" to this kind of bad-news context: Military use of nuclear technology stories were comparatively often rated as containing such features. To some extent, these contextual features also tended to coincide in stories overall: stories reporting public anxiety often reported expressed contempt for risk regulators (Tønnessen et al. 1995).

Considering such results, it must be remembered that part of the media coverage centred much on the question of how the risk, and importantly, how public information about the risk, were handled by the authorities. Perhaps anxiety, ethical dimensions, and contempt turned against risk regulators are more easily generated in the case of hazards with which people generally lack direct experience ("low probability high consequence risks") the plausible logic being that "alienation breeds contempt"?

Another explanation with regard to nuclear issues might be found by looking ten years back in time. After the Chernobyl accident, the authorities gradually came to be criticised for contradictory and inadequate information - by the public as well as by the print media (NOU 1986:19). Even though some researchers have used the term "information crises" also about the situation in Sweden in May 1986 (Nohrstedt, 1990), research done by Mårdberg and colleagues ${ }^{10}$ in Sweden and Weisæth and colleagues $^{11}$ in Norway, have documented rather large national differences (Mårdberg et al. 1987, Weisæth 1991, Tønnessen et al submitted). In their survey research they found that seven out of ten in Sweden understood a fair share or all of the mass media coverage of the accident as compared to only four out of ten in Norway. Furthermore, some five out of ten in Sweden felt that the information provided by experts and authorities through the mass media was of rather bad or very bad guidance as compared to nearly eight out of ten responding likewise in Norway. In harmony with these differences it was found that six out of ten in Norway had rather small or very small confidence in information provided by experts and authorities as compared to four out of ten in Sweden. In Sweden it was also demonstrated a higher degree of mistrust among the population in the more affected area of Gävle ${ }^{12}$.

The same rather large differences between the two countries were confirmed when asking the Swedish and Norwegian population retrospectively some ten years after if they believed the authorities gave full and correct information in 1986. Whereas only two out of ten Norwegians believed their authorities to have been given full and correct information, the same figure for the Swedish population was found to be more than five out of ten (Sjöberg et al. 2000: 76). To conclude, the survey results thus demonstrate that there where indeed problems and ambiguities with the information provided to the Swedish public by authorities and experts, but overall the severity of the information problems in Norway was of quite another degree. 
Something that may speak against the speculations above is the finding that references to blame were remarkably rare in stories treating the Chernobyl accident and East European nuclear power plants - particularly in Norway. Remarkably, for two reasons: First, the design faults in the Chernobyl reactor and others of the same type, together with insufficient operational security measures, are deficiencies which might very well be attributed to individuals or agencies. Secondly, the Chernobyl accident was initiated by a badly designed and unauthorised experiment, for which the persons behind it might be blamed (Stang 1996; Wilkins \& Patterson 1987). Although these deficiencies were reported, they did not give rise to attributions of blame or recriminations.

Another concern of the present study was the extent to which comparisons were made between the "primary" hazard focussed upon by the story and any other hazard touched upon in the same article. In general, comparisons making any kind of evaluative claim were rare (in less than 10 per cent of the stories in both countries). In both Norway and Sweden, three types of risk were more often treated in a comparatively manner than others: East European nuclear power plants and The Chernobyl accident in both countries and Radiation from inhome radon gas in Norway and Domestic nuclear power plants in Sweden. East European nuclear power plants in both countries came out "worst", frequently unfavourably compared with other hazardous installations, whereas Domestic nuclear power plants, not very surprisingly, was an hazard portrayed as representing less risk than its points of references.

Analyses showed that when a "secondary" hazard was given space in a story, the connection was rational. The most evident example of such a tendency was that stories dealing primarily with East European nuclear power plants contained references to the Chernobyl accident (and in Sweden also to Domestic nuclear power plants). Secondly, stories about nuclear hazards frequently brought up the aspect of food contaminated by radioactive substances. Such a connection came out strongly especially in the stories treating The Chernobyl accident, but in Norway also in stories treating Military use of nuclear technology.

\section{Sources of Risk Information}

The analysis of risk sources revealed that overall, authorities and experts were given a rather prom- inent position as risk definers. Nelkin provides a reasonable explanation for such a situation though referring specifically to governmental authorities: such sources are "often [...] well informed and as well able to offer the journalist a credible and more or less "ready-made" picture of the situation, easily summarised into a news story." (Nelkin 1987, in Hannigan 1995:66). Naturally, the information received in this manner are bound to be more or less tied to vested interests, but according to Nelkin (1989:63) this is a problem poorly considered by the journalists dealing with scientific and technological issues (Nelkin 1995, Djerf Pierre 1996:353f, Wilkins 1993). This problem is clearly linked to the role attributed to the journalist; should the reporter act as a passive, but efficient, mediator of information, or as a critical watchdog? In situations when expert knowledge amongst journalists is lacking, the second alternative is obviously not very likely (NOU 1986:19:218).

The results from the present analysis reveal that journalists did not stand out as totally passive in their role as mediators of risk information. Theirs was the only voice perceptible in 20 per cent of the stories. In the Chernobyl stories, the figure went as high as 40 per cent. If we also include the stories where news agencies and other media channels appeared as risk definers, we see that in Norway, the media sources accounted for more than half of the stories reporting on nuclear waste, compared to fewer than 40 per cent for this type of risk in Sweden.

Wilkins (1989:173) points at a difficulty in risk reporting connected with the high proportion of media attention paid to the establishment to the exclusion of other actors or aspects: the focus tends to be put on the political debate per se - at the expense of scientific aspects. In the present analysis, Air pollution and East European nuclear power plants were the hazards most "affected" in this sense in both countries. The risk statements regarding both these hazards originated from the authorities (including the government) and other politicians/political parties in almost 50 per cent of the stories in Sweden, and in almost 40 per cent in Norway. Such a result indicates that the political dimension largely directed the coverage of these issues. Experts, in contrast, appeared without competition as sources in no more than 20 per cent of any type of risk story, except for Radiation from in-home radon gas in Norway where they accounted for 60 per cent of all sources. The same category of story was also the most generous when it came to allowing 
individuals - in the role of (potential) victims or not - to give their view on the issue, i.e. in 17 per cent.

Two broad categories of story type were distinguished: "primarily subjectively held sections" as opposed to the more "objectively held" formats. The former category refers to article placement in sections containing editorials, debate articles, letters, and other kind of commentaries, whereas the latter comprises more "typical" or straightforward news sections. Objectively held sections accounted for more than four times as many stories as did subjectively held sections. Sources in the objectively held sections placed dominance on establishment and expert sources. In contrast, within subjectively held sections, the sources or "risk definers" in both countries clearly ranked differently compared with the total set of stories. In Sweden individuals representing no one but themselves (letter writers) and editorial writers dominated the scene, accounting for respectively more than one third and almost one quarter of all stories. In Norway these two groups, together with interest groups, accounted for approximately one sixth each.

Dominance for authority and expert sources was not a valid feature for the risk story sample overall. Thus, unexpectedly, the "command post point of view" often referred to as characterising risk and disaster reporting in the media (Quarantelli 1991a:34f), here was not found.

\section{Risk Reporting and the Principle of News Value}

As mentioned above, there is no one obviously adequate way to inform about risk. The mass media have to deal with "a diversity of incoming messages caused by different perspectives on the nature of the risk and its best management" (Renn 1992:480). This indicates the importance of the newspapers' choice of risk information sources. The source used, or otherwise attended to, is likely to affect the information received. Risk managers, for instance, in the search for general risk features making it possible to compare one risk event with another, tend to focus on probabilities and other kinds of abstract information, whilst for instance the eye-witnesses of an accident tend to dwell upon more specific details of the event (Renn 1992:473).

Risk articles were coded on the extent to which they contained certain specific descriptive features, such as references to scientific research, information about numbers of people affected by the risk, risk probabilities, and practical advice. Of these, references to scientific research (broadly interpreted), represented the most common feature, found in one quarter of the stories in Norway and in almost one sixth in Sweden. Such references were most common in the stories about Radiation from in-home radon gas and Military use of nuclear technology in Norway, and in the stories about The Chernobyl accident in Sweden.

Amongst the types of quantitative information considered in the analysis, the most frequently occurring was that of references to numbers of people affected in the past. Information about numbers of people likely to be affected in the future, risk probabilities, percentage change in risk or other kinds of risk estimates, were seldom provided. Similar observations have been made in other studies of risk reporting in the media (Greenberg et al. 1989b, Singer \& Endreny 1993:85ff, Freimuth et al. 1984), but counter-examples can be found (Ryan et al. 1991). Some of the variation in this regard might stem from the limitative nature of the sample and the coding system. The coding definitions stipulated in the present analysis were quite narrow, suggesting that the results should be interpreted as displaying minimum values rather than anything else.

In the cases where risk estimates were provided, the proportion between confident estimates and those including some kind of uncertainty was generally quite balanced. However, in the stories most often presenting risk estimates, The Chernobyl accident in both countries and Radiation from inhome radon gas in Norway, uncertain estimates were more than twice as common as confident ones. Such a result offers little support to Hannigan (1995:71) in stating that: "Journalists have little patience with the thrusts and parries of scientific debate: either a danger exists or it does not.". Nevertheless, the fact that risk estimates on the whole represented a rare feature in the coverage might indicate that the journalists were not very concerned about finding and providing any such quantitative measures linked with the risk. At the same time, it should be kept in mind that risk estimates are often very hard to produce, even with the best scientific competence; such information may not have often been available even from expert or authority sources consulted.

Be that as it may, "public understanding of risk is a multidimensional concept and cannot be reduced to the product of probabilities and consequences" (Renn 1992:478 cf. Sandman et al. 1987). Testimonials, i.e. personal experiences of risk, could give access to these other kinds of dimen- 
sions. Our results suggest that the use of such sources of risk information is far from widespread, being found in not more than about five per cent of all stories. Most often, testimonials were found in the stories treating Military use of nuclear technology in Norway and in the stories treating The Chernobyl accident in Sweden. However, we cannot conclude directly that the risk stories contained only "depersonalised" information or only that originally provided by professional risk managers. The frequency of testimonials as measured in the present analysis most likely underestimates the occurrence of information based on direct risk experience and the like. This is particularly the case regarding feature stories, in which the journalist often expresses his or her own reflections about the risk situation, based on the impression received from interviews.

Risk and specific risk qualities are often debated, by scientists as well as by the general public. Those involved in public information strategies in their work are faced with the difficult task of balancing the wish for consistent information and the demand for "realistic openness" (Waldahl 1995), and this is naturally something with implications also for journalistic work. For, as Moore (1989:6) states: "Science is nearly always an ambiguous enterprise, and journalists who cover it have to cope with that fact.". Moreover, Nelkin (1989:59) finds that "journalistic norms lead reporters to adopt a polarised approach to the prob- lem, emphasising conflict rather than knowledge, and this results in a reporting of evidence that is often inconsistent and confused" (cf. e.g. Dunwoody \& Peters 1992:210f; Greenberg et al. 1989a:120; cf. Asp 1988)

In the present analysis, 6 per cent of the risk stories on average contained some kind of conflicting risk statements. The individual hazards gathered between 2 and 14 per cent. Thus, it does not seem as if the journalists to any appreciable extent used this kind of possibility to dramatise the stories. The nuclear hazards, including The Chernobyl accident, represented no obvious exception in this regard. This despite the fact that, as Rubin (1987:53) points out, there are "few recognisably 'neutral' sources for reporters to consult in a nuclear accident", nor any single "truth" easily available in the search for more general risk estimates concerning radioactive contamination (Tønnessen et al. 1995:275).

As we have seen, the Chernobyl accident, as well as the other nuclear risk items covered by the present study, received quite a lot of media attention at the time of the tenth anniversary and, furthermore, were given a rather prominent position as news issues. What reasons might there be for such a result? Hvitfelt (1985) lists some factors he has found contributing to the possibility for a story to make it to the front page, which we will apply. In the following table, we line up Hvitfelt's definition with aspects of the Chernobyl accident.

\section{Table 3. Hvitfelt's Factors for an "Ideal" News Story Applied on the Chernobyl Accident}

\section{An "ideal" news story should be based on:}

- a political or economical issue, or a crime or an accident,

- within a short geographically or cultural distance, to

- events and situations which are

- sensational and surprising,

- deals with single elite persons, and

- $\quad$ are described simply enough, but

- are important and relevant, and are

- $\quad$ taking place within a short period of time, but as a part of a theme, and

- involves negative aspects, and

- $\quad$ are told by the use of elite sources.
The Chernobyl accident contain the major part of these aspects, representing:

- a severe accident (or even a catastrophe),

- which resulted in consequences for the Norwegian and Swedish population,

- being, in a retrospective way of looking at it, clearly event centred,

- being sensational as well as surprising when it happened,

- being important enough to involve elite persons,

- being "simple", in the sense that it provides an "event" with causes and consequences natural to focus on,

- being important and relevant with regard to both the political life and to the concerned public,

- took place in a short period of time, but could easily be brought into the context of the future role of nuclear power

- involved definitively negative aspects;

- $\quad$ involved elite sources that had something to say on the subject. 
The tenth anniversary served as a "news peg", making it possible to bring the accident onto the public agenda again. The anniversary per se was, obviously, not a surprise, although referring to an event that happened a long time ago. The relevance of the accident at that earlier time was strong, as populations in each country felt direct or indirect impacts on their daily life. The accident had, however, contemporary relevance to Sweden as a country relying on nuclear power, to Norway due to its involvement in nuclear safety projects, and to both countries facing possible future exposure to new nuclear accidents, domestic or foreign. Such relevance is of course a crucial factor when it comes to "anniversary journalism". Furthermore, fires, representing new "events" on the media scene, were reported from the surrounding area of the Chernobyl plant in the spring of 1996, something that naturally also served to "remind" the journalists of the accident.

All these factors related to the Chernobyl accident might be transferred also to East European nuclear power plants in general, as well as to other nuclear hazards as Nuclear waste and Military use of nuclear technology. These hazards are all good examples of technological risks and as such are often regarded as inevitable and thus intrinsically newsworthy (Nelkin 1989:70). Inevitable as nuclear risks may be, they might also be classified as "low probability high consequence risks". Independently of the terms used, what it all adds up to is the fact that nuclear risks are more likely than others to be considered newsworthy by journalistic standards (Singer and Endreny 1987:10ff, Greenberg et al. 1989a\&b). ${ }^{13}$ The present study supports this thesis.

\section{Conclusion}

Concerned with media content and media message, this study has demonstrated that considerable attention is paid to a great number of hazards by the newspapers investigated. At first sight, road traffic accidents seem to represent the main risk issue, accounting for about one fifth of the total volume devoted to the twenty different hazard items included in our sample, both in Norway and Sweden. This picture was, however, somewhat modified when we turned to other aspects of media attention than that of number of published stories. The other hazards were to a greater extent treated in other kinds of stories than basic news stories (analyses, commentaries etc.), and these stories, with reference espe- cially to the nuclear items, were in general more voluminous. Altogether, both Norwegian and Swedish newspapers give noticeable attention to the various radiation risks as compared to other risk issues, even taking into consideration that our period includes the ten-year anniversary of the Chernobyl accident

Narrowing down the focus to the IoR risks treated in full extent in the present analyses, we have seen that the nuclear issues ranked high in terms of other factors pointing at their prominence as news stories. This is also the case when we use other frequently covered risk issues, air pollution, chemical waste, and radon, as points of references. Moreover, the nuclear stories characterises themselves in the following ways.

- As expected, the Chernobyl risk stories occurred in a focused pattern around April $26^{\text {th }}$. The fact that four out of ten Chernobyl items was found in the April $25-27^{\text {th }}$ period, and seven out of ten occurred in the period five days before - five days after April $26^{\text {th }}$ give indications that eventual effect studies on public risk perception must be attentive to a very limited time period ${ }^{14}$.

- Nuclear hazards were treated in an overall alarming way both in Norway and Sweden, even if the Swedish newspapers made a clear distinction between domestic and foreign items, treating domestic nuclear power plants and nuclear waste in a much more reassuring way than the other nuclear hazards. Consequences of a risk upon people or the environment, however, in spite of this alarming perspective, were not very prominent in the risk stories. When a story had such a focus it most often referred to effects on human health.

- Comparisons with other risks were rare, practical advice about how to handle the situation seldom was given, and information about a hazard as totally or partially controllable were mentioned in very few stories in the Norwegian newspapers. Measures taken by society in order to prevent the risk from becoming reality were, however, provided in about half of all stories in both countries.

- The journalists themselves and news agencies accounted, however, for about a third of all stories, which means that the newspapers did not stand out as passive mediators of risk information. Authority and expert sources were also given a rather prominent position as risk defin- 
ers, but the experts did not have as strong a position as one might expect in a field dominated by scientific and technological questions.

This comparison between the coverage of radiation risks in Norwegian and Swedish newspapers has revealed some differences between the two countries, most of them owing to Sweden's status as a nuclear energy nation. One major difference resulting form this contextual difference was the finding that about one third of the IoR risks stories in Sweden primarily concerned domestic nuclear power compared to none in Norway. As some of these stories possibly is a part of the ongoing political debate about phasing out nuclear power in Sweden, it is not easily established to what "other " IoR risk these domestic nuclear power risk stories should be compared. However, if the IoR risk stories in Sweden treating domestic nuclear power are compared to the rest of the Swedish IoR risk stories, they were found more often to be overall reassuring and more often providing comparison with other risks portrayed as larger. It is also noteworthy that the domestic nuclear power stories show a slight peak in coverage exactly in the week of the Chernobyl commemoration date. The Norwegian newspaper coverage of IoR risks more often contained a focus on Military uses of nuclear technology, with a particular weight put on the conditions at the Kola peninsula.

However, turning to the explicit Chernobyl risk stories, the similarities are more pronounced than the dissimilarities, and our main conclusion is that the newspapers in the two countries present more or less the same picture as far as risk reporting of the Chernobyl commemoration is concerned.

Media content does not, however, equal media effects. Perception of risk is a psychological and social process, involving other factors than merely informative ones. Theory and research support the existence of media effects on risk perception, but research is less able to discern and measure the factors involved in these processes (af Wåhlberg and Sjöberg 2000), and we know that the media is only one factor among many. The present study has thrown some light on the media's role in the risk communication processes of modern society, but we have obviously not answered the questions of to what extent and in what ways the newspapers may have influenced their readers.

\section{Notes}

1. The present article is a further analysis of material previously published in two national reports, one from Sweden (Nilsson et al. 1997a) and one from Norway (Nilsson et al. 1997b). Both these reports originated within the RISKPERCOM project, a European Commission sponsored project (contract no. F14P-T950016, DG12-WSMW) involving France, Norway, Spain, Sweden and UK, and co-ordinated by L. Sjöberg. The Norwegian partner has been financed by grant from the NFR. The RISKPERCOM national project leaders and involved institutions in the various countries are: France: Dr Jean Brenot, Institut De Protection et de Surete Nucleaire (IPSN), Norway: Dr. Jon B. Reitan, Norwegian Radiation Protection Authority (NRPA), Spain: Dr. Ana Prades Lopez, Centro de Investigaciones Energeticas, Medioambientales y Tecnologicas (CIMEAT), Sweden: Professor Lennart Sjöberg, Center for Risk Research (CRR), UK: Dr. Lynn Frewer, Institute of Food Research (IFR). We will like to thank Claire Mays from the French team for valuable comments to this article.

2. Radiation with less energy than that required to produce ions in the irradiated material, is called nonIoR. Ultraviolet radiation (except the high-energy end

of the UV-spectrum), visible light, infrared radiation, micro-waves and radio waves, are all non-ionising.

3. Dagens Nyheter and Göteborgs-Posten.

4. The UK Government on March 26th 1996 announced the result of research by Will and colleagues (1996) that proposed a possible link between bovine spongiform encephalopathy BSE in cattle and what they identified to be a new variant of Creutzfeldt-Jakob disease (nvCJD/vCJD). The disease was initially labelled new variant CJD (nvCJD), and is now known as variant CJD (vCJD). The ramifications of that announcement have been extensive and profound, politically and economically, and have had impact on the general public in the UK and other countries. For instance according to data from the UK Ministry of Agriculture, Fisheries and Food (MAFF), the meat and veal consumption by the UK public sank on average some $16 \%$ in the three years after the announcement (data found at: http://www.maff.gov.uk/esg/default. htm). By March 30th 2000 there were 51 confirmed and two probable deaths from vCJD, and 12 still living patients with probable vCJD in the UK (http://www. cjd.ed.ac.uk/). Creutzfeldt-Jakob Disease (CJD) was first described in the 1920s and is one of a group of diseases called transmissible spongiform encephalopathies (TSEs) which can occur in people or animals. 
Creutzfeldt-Jakob Disease is the commonest of the human TSEs but it is still rare with an annual incidence across the world of 0.5 to 1.0 cases per million of the population. The diseases have a prolonged incubation period and are characterised by an invariably fatal degeneration of the nervous system.

5. It might possibly have diminished the volume of ionising radiation risk stories, but this is an empirical question that the current paper partly will investigate.

6. Circulation figures and place of publication for each newspaper.

\section{Sweden:}

Expressen (413 200, Stockholm), Dagens Nyheter (374 200, Stockholm), Aftonbladet (362 000, Stockholm), Göteborgs-Posten (269 700, Göteborg), Svenska Dagbladet (194 900, Stockholm), Gefle Dagblad (31 500, Gävle).

Source: TS-boken. Dagspressregister 1.1 - 31.12 1995.

Norway:

Aftenposten (morning ed.) (288 635, Oslo), Dagbladet (205 740, Oslo), Adresseavisen (91 912, Trondheim), Oppland Arbeiderblad (28 521, Gjøvik), Valdres (10 158, Fagernes).

Source: NAL (Norwegian Newspaper Publishers' Association). Data referring to the year of 1996.

7. For a modified and even contradictory view, see Gaddy and Tanjong (1986) and Freudenburg et al. (1996).

8. A primary move in this direction is naturally to ensure an acceptable level of knowledge amongst the mediators of risk information. The Norwegian official report written as a response to the Chernobyl accident (NOU 1986:19), pointed exactly at lack of knowledge amongst journalists as a plausible explanation for the small amount of background information.

9. The dimension of conflict, often linked to that of morals and blame, might be said to represent an important element in the "social dramas" taking place in the media (Hannigan 1995:69; Nelkin 1989:53ff; 1995:62).

10. At the FOA-55 Behavioural Science Department of the National Defence Research Establishment (=FOA).

11. At KKP Division of Disaster Psychiatry at the University of Oslo.

12. In Norway the fallout situation at the time of Weisæth's interviews was not at all so established making it impossible to do special sub sampling in affected areas as Mårdberg did in the more affected Gävle region in Sweden.

13. It has been argued that the differences between natural disasters and those of technological origin are less prominent than are their similarities (Quarantelli 1991b). Thus, it is not necessarily the case that media coverage on nuclear disasters should significantly differ from that on other "low probability high consequence risks".

14. This indicate that one possible weakness in the three wave public survey design in the RISKPERCOM study may be related to the fact that the duration of each wave and the time period between the waves may have been to long. Survey interviews for the possible effects of mass media coverage of the Chernobyl commemoration should probably have occurred in a very condensed manner perhaps starting some 6 days after the commemoration date.

\section{References}

Adams, William C. (1986) "Whose Lives Count?: TV Coverage of Natural Disasters", Journal of Communication, 36(2): 113-122.

Asp, Kent (1988) "Politisk journalistik - Studier i mediernas partiskhet och makt", in Ulla Carlsson (ed.) Forskning om Journalistik, Nordicom-Nytt/Sverige 4-88.

Beck, Ulrich (1986) Risk Society. Towards a New Modernity. London: Sage.

Cohn, Victor (1989) "Reporters as Gatekeepers", in Mike Moore (ed.) Health Risks and the Press: Perspectives on Media Coverage of Risk Assessment and Health. Washington, D.C.: The Media Institute (in cooperation with the American Medical Association, Chicago, Illinois).

Combs, Barbara \& Slovic, Paul (1979) Newspaper Coverage of Causes of Death. Journalism Quarterly, 56(4): 837-843; 849 .

Djerf Pierre, Monika (1996) Gröna Nyheter-Miljöjournalistiken i televisionens nyhetssändningar 1961-1994. Göteborg University: Department of Journalism and Mass Communication.

Drottz-Sjöberg, Britt-Marie (1991) Perception of Risk. Studies of Risk Attitudes, Perceptions and Definitions. Stockholm: Stockholm School of Economics, Centre for Risk Research (Doctoral Thesis).

Dunwoody, Sharon \& Peters, Hans Peter (1992) "Mass Media Coverage of Technological and Environmental Risks: A Survey of Research in the United States and Germany", Public Understanding of Science, 1: 199230.

Freimuth, Vicki S.; Greenberg, Rachel H.; DeWitt, Jean \& Romano, Rose Mary (1984) "Covering Cancer: Newspapers and the Public Interest", Journal of Communication, 34(1): 62-73.

Freudenburg, William R.; Coleman, Cynthia-Lou; Gonzales, James \& Helgeland, Catherine (1996) "Media Coverage of Hazard Events: Analyzing the Assumptions", Risk Analysis, 16(1): 31-42.

Gaddy, Gary D. \& Tanjong, Enoh (1986) "Earthquake Coverage by the Western Press", Journal of Communication, 36 (2): 105-112.

Gorney, Carole (1992) "Numbers versus Pictures: Did Network Television Sensationalize Chernobyl Coverage?", Journalism Quarterly, 69(2): 455-465.

Greenberg, Michael R.; Sachsman, David B.; Sandman, Peter M. \& Salomone, Kandice L. (1989a) "Network Evening News Coverage of Environmental Risk", Risk Analysis, 9(1): 119-126. 
Greenberg, Michael R.; Sachsman, David B.; Sandman, Peter M. \& Salomone, Kandice L. (1989b) "Risk, Drama and Geography in Coverage of Environmental Risk by Network TV", Journalism Quarterly, 66(2): 267277.

Hannigan, John A. (1995) Environmental Sociology - A Social Constructionist Perspective. London: Routledge.

Holmberg, Sören \& Asp, Kent (1984) Kampen om kärnkraften. En bok om väljare, massmedier och folkomröstningen 1980. Stockholm: Liber förlag.

Hvitfelt, Håkan (1985) På första sidan - En studie $i$ nyhetsvärdering. Stockholm: Beredskapsnämnden för psykologiskt försvar [National board of psychological defence], Report no. 131.

Hvitfelt, Håkan (1986) Difteri i pressen - En analys av nyhetsbevakningen och informationen om difterismitta i Göteborg. Stockholm: Styrelsen för Psykologiskt Försvar [National board of psychological defence], Report no. 135.

Luhman, Niklas (1993) Risk: A Sociological Theory. Berlin: Walter de Gruyter \& Co.

Mazur, Allan \& Lee, Jinling (1993) "Sounding the Global Alarm: Environmental Issues in the US National News", Social Studies of Science, 23(4): 681-720.

Maibach, Edward \& Parrot Roxanne Louisielle (eds.) (1995) Designing Health Messages - Approaches from Communication Theory and Public Health Practice. London: Sage.

Moore, Mike (1989) "Beware the Bracken Fern", in Mike Moore (ed.) Health Risks and the Press: Perspectives on Media Coverage of Risk Assessment and Health, Washington, D.C.:The Media Institute (in cooperation with the American Medical Association, Chicago, Illinois).

Mærlie, Morten Bremer (1999) Atomterrorisme. Oslo: NUPI (Norwegian Institute of International affairs).

Mårdberg, Bertil; Ulf, Otto \& Lundin, Tom (1987) The Population's Reactions to the Threat from the Chernobyl Accident. Stockholm: The National Defence Research Establishment, Internal working document, FOA-55 PM 55:114 (In Swedish).

Nelkin, Dorothy (1989) "Journalism and Science - The Creative Tension", in Mike Moore (ed.) Health Risks and the Press: Perspectives on Media Coverage of Risk Assessment and Health. Washington, D.C.: The Media Institute (in cooperation with the American Medical Association, Chicago, Illinois).

Nelkin, Dorothy (1995) Selling Science - How the Press Covers Science and Technology. (revised ed.), New York: W.H. Freeman \& Co.

Nimmo, Dan \& Combs, James E. (1985) Nightly Horrors Crisis Coverage by Television Network News. Knoxville: The University of Tennessee Press.

Nilsson, Åsa; af Wåhlberg, Anders \& Sjöberg, Lennart (1997a) Ten Years After the Chernobyl Accident: The Reporting on Nuclear and Other Hazards in Six Swedish Newspapers. Stockholm School of Econo- mics, Center for Risk Research, RHIZIKON: Risk Research Report nr 28.

Nilsson, Åsa; Reitan, Jon; Tønnessen, Arnfinn \& Waldahl, Ragnar (1997b) Radiation and other Risk Issues in Norwegian Newspapers Ten Years after Chernobyl. Østerås: Norwegian Radiation Protection Authority, Report 1997:8.

Nohrstedt, Stig Arne (1990) The Information Crises in Sweden after Chernobyl. Media Culture and Society 13.

NOU 1986:19 Informasjonskriser. Oslo/Bergen/Stavanger/ Troms $\varnothing$ : Universitets-forlaget A/S.

Quarantelli, E.L. (1991a) Lessons from Research: Findings on Mass Communication System Behavior in the Pre, Trans, and Postimpact Periods. University of Delaware: Disaster Research Center, Article \#227.

Quarantelli, E.L. (1991b) "Radiation Disasters: Similarities to and Differences from Other Disasters", in Robert C. Ricks et al. (eds.) The Medical Basis for RadiationAccident Preparedness III. The Psychological Perspective. New York/Amsterdam/London/Tokyo: Elsevier, pp 15-24.

Renn, Ortwin (1992) "Risk Communication: Towards a Rational Discourse with the Public", Journal of Hazardous Materials, 29(3): 465-519.

Rosengren, Karl Erik (1970) "International News: Intra and Extra Media Data", Acta Sociologica 13(2): 96-109.

Rubin, David M. (1987) "How the News Media Reported on Three Mile Island and Chernobyl", Journal of Communication, 37(3), 42-57.

Ryan, Michael; Dunwoody, Sharon \& Tankard, James (1991) "Risk Information for Public Consumption: Print Media Coverage of Two Risky Situations", Health Education Quarterly, 18(3): 375-390.

Sandman, Peter M.; Weinstein, Neil D. \& Klotz, M.L. (1987) "Public Response to the Risk from Geological Radon", Journal of Communication, 37(3): 93-108.

Sandman, Peter M.; Miller, Paul M.; Johnson, Branden B. \& Weinstein, Neil D. (1993) "Agency Communication, Community Outrage, and Perception of Risk: Three Simulation Experiments", Risk Analysis, 13(6): 585597.

Singer, Eleanor (1990) "A Question of Accuracy: How Journalists and Scientists Report Research on Hazards", Journal of Communication, 40(4): 102-116.

Singer, Eleanor \& Endreny, Phyllis (1987) "Reporting Hazards: Their Benefits and Costs", Journal of Communication, 37(3): 10-26.

Singer, Eleanor \& Endreny, Phyllis M. (1993) Reporting on Risk - How the Mass Media Portray Accidents, Diseases, Disasters, and Other Hazards. New York: Russell Sage Foundation.

Sjöberg, Lennart; Jansson, Bengt; Brenot, Jean; Frewer, Lynn; Prades, Anna, \& Tønnessen, Arnfinn (2000) Risk Perception in Commemoration of Chernobyl: A Cross-National Study. Stockholm: School of Economics, Center for Risk Research, RHIZIKON: Risk Research Report nr 33. 
Skurdal, Jostein; Vagstein, Geir \& Thørve, Irene (1987) Radioaktivitet $i$ Oppland etter Tsjernobyl - virkninger for fisk og vilt. Miljøvernavdelingen, Fylkesmannen i Oppland, Report no. 6-1987.

Slovic, Paul (1987) Perception of Risk Science vol. 236.

Smyser, Richard D. (1991) "The Role of Media in Minimizing Anxiety in Radiation Accidents", in Robert C. Ricks et al. (eds.) The Medical Basis for RadiationAccident Preparedness III. The Psychological Perspective. Elsevier, New York/Amsterdam/London/ Tokyo, pp 243-251.

Sood, Rahul; Stockdale, Geoffrey \& Rogers, Everett M. (1987) "How the News Media Operate in Natural Disasters", Journal of Communication 37(3): 27-41.

Stang, E. (1996) Chernobyl - System Accident or Human Error. Radiation Protection Dosimetry, 68(3/4): 197 201.

Tønnessen, Arnfinn; Reitan, Jon B.; Strand, Per; Waldahl, Ragnar \& Weisæth, Lars (1995) "Interpretation of Radiation Risk by the Norwegian Population: A National Survey in 1993", in Gunnar Sundnes (ed.) Biomedical and Psychosocial Consequences of Radiation from Man-made Radionuclides in the Biosphere. Trondheim: Tapir.

Tønnessen, Arnfinn; Weisæth, Lars \& Mårdberg, Bertil (submitted) Silent Disaster: a European and Scandinavian Perspective on Chernobyl Fallout.

Waldahl, Ragnar (1995) "Public Information Strategies", Radiation Protection Dosimetry, 62(1/2): 107-111.

Weisæth, Lars (1991) Psychosocial Reactions in Norway to Nuclear Fallout from the Chernobyl Disaster, in Couch, S.R. and Kroll-Smith, J.S. (eds) Communities at Risk. Collective Responses to Technological Hazards. New York: Peter Lang Publishing, pp. 53-80.

Westerståhl, Jörgen \& Johansson, Folke (1985) Bilden av Sverige - Studier av nyheter och nyhetsideologier $i$ $T V$, radio och dagspress. Stockholm: SNS Förlag.

Wiegman, Oene; Gutteling, Jan M.; Boer, Henk \& Houwen, Reinder J. (1989) "Newspaper Coverage of Hazards and the Reactions of Readers", Journalism Quarterly, 6 (4): 846-852, 863

Wilkins, Lee (1986) "Media Coverage of the Bhopal Disaster: A Cultural Myth in the Making", International Journal of Mass Emergencies and Disasters, 4(1): 7 33.

Wilkins, Lee (1989) "Conclusion: Accidents will Happen", in Lynne Masel Walters et al. (eds.) Bad Tidings: Communication and Catastrophe. New Jersey: Hillsdale; Hove/London: Lawrence Erlbaum Associates.

Wilkins, Lee (1993) "Between Facts and Values: Print Media Coverage of the Greenhouse Effect, 1987-1990", Public Understanding of Science, 2: 71-84.

Wilkins, Lee \& Patterson, Philip (1987) "Risk Analysis and the Construction of News", Journal of Communication, 37(3): 80-92.

Will, R.G.; Ironside, J.W.; Zeidler, M; Cousens, S.N.; Estibeiro, K.; Alperovitch, A.; Poser, S.; Pocchiari, M. Hofman, A. \& Smith, P.G. (1996). A New Variant of Creutzfeldt-Jakob Disease in the UK. Lancet 347: 921-925.

af Wåhlberg, Anders \& Sjøberg, Lennart (2000) Risk Perception and the Media. A Review of Research on Media Influence on Risk Perception. Journal of Risk Research 3(1)31-50, 